OPEN ACCESS

Edited by:

Massimiliano Cardinale, Swedish University of Agricultural

Sciences, Sweden

Reviewed by:

Fabio Pranovi,

Ca' Foscari University of Venice, Italy

Laura Uusitalo,

Finnish Environment Institute (SYKE),

Finland

*Correspondence:

Ilaria Vielmini

ivielmini@oceana.org

Specialty section:

This article was submitted to

Marine Fisheries, Aquaculture and

Living Resources,

a section of the journal

Frontiers in Marine Science

Received: 17 March 2017

Accepted: 09 June 2017

Published: 22 June 2017

Citation:

Vielmini I, Perry AL and Cornax MJ

(2017) Untying the Mediterranean Gordian Knot: A Twenty First Century Challenge for Fisheries Management.

Front. Mar. Sci. 4:195.

doi: 10.3389/fmars.2017.00195

\section{Untying the Mediterranean Gordian Knot: A Twenty First Century Challenge for Fisheries Management}

\author{
Ilaria Vielmini *, Allison L. Perry and María José Cornax \\ Fundacíon Oceana, Madrid, Spain
}

Management of fisheries in the Mediterranean basin has often been described as a unique and complex challenge, due to their multi-specificity, the diversity of gear-types, and the number of nations involved. This perspective has gone hand-in-hand for decades with a lack of strong political will from decision-makers, who have been unwilling to put Mediterranean fisheries management high on their agendas. Over time, exploitation rates of demersal stocks have increased and in 2016, $97 \%$ of shared stocks assessed in the Mediterranean were reported to be overfished. An alarm bell about the chronic overfishing of Mediterranean fish stocks was rung by European policy makers in 2015, exactly 20 years after the Code of Conduct for Responsible Fisheries adopted by the Food and Agriculture Organization mandated that states should ensure the sustainable use of fishery resources. In this perspective, we: (i) review the context of fisheries management in the Mediterranean; (ii) identify the potential factors that may have hindered management and; (iii) discuss how the reformed European Union Common Fisheries Policy and the binding commitments laid down in its text may lead to knock-on effects for fisheries management in the international Mediterranean context, if properly implemented. In this line, we also present the example of demersal fisheries management in the Strait of Sicily, which may represent a starting point for science-based management in the Mediterranean.

Keywords: Mediterranean, overfishing, policy, knock-on effect, Common Fisheries Policy

\section{THE LONG ROAD TO MANAGEMENT OF SHARED MEDITERRANEAN FISH STOCKS}

The need for effective management of shared fisheries resources in the Mediterranean Sea was first highlighted during the aftermath of the Second World War. In 1948, the 4th Session of the FAO Conference agreed to set up an international organization dedicated to Mediterranean fisheries management, which was formalized with the 1952 establishment of the General Fisheries Council for the Mediterranean. This preliminary attempt to manage fisheries in the region was limited in its powers; the measures adopted by the Council were not binding for the Signatory States and it lacked operational activity (OECD, 2005). At time, information on the status of Mediterranean stocks was very limited and mainly relied on FAO statistics, with their limitations of negligible catches reported for many species (STECF, 2015). Periodic updates aimed at assessing the status of demersal and small pelagic Mediterranean resources only began to be carried out from 1970 onwards (FAO, 1999). 
When the United Nations Convention on the Law of the Sea (UNCLOS) entered into force in 1994, requiring all members to cooperate in the conservation and management of living marine resources, the General Fisheries Council for the Mediterranean was the oldest Regional Fisheries Management Organization (RFMO) in the world. However, it was still far from acting as such, since its constitutive text lacked a clear mandate and objectives. In parallel, the mid-90s were marked by the adoption of the FAO Code of Conduct for Responsible Fisheries (1995) and the Straddling Fish Stocks and Highly Migratory Species Agreement (UN, 1995), which formally called for the establishment of the RFMOs.

As a consequence of this international process to modernize management of shared stocks, in 1997 the General Fisheries Council for the Mediterranean revised its Agreement and became the General Fisheries Commission for the Mediterranean (GFCM, hereafter). A Scientific Advisory Committee (SAC) was also established, with the task of annually conducting and validating stock assessments. The amended Agreement entered into force in 2004. This change represented the key milestone for fisheries management in the region. In 2005, GFCM was fully empowered as an RFMO responsible for adopting binding fisheries management rules for transboundary fish stocks.

Nowadays, GFCM has under its purview the management of shared demersal and small pelagic stocks, which for management purposes are divided into 30 geographical sub-areas (GSAs) in the Mediterranean and Black Seas. It is composed of 24 Members (23 member countries and the European Union) and three Cooperating non-Contracting Parties (i.e., Bosnia and Herzegovina, Georgia and Ukraine).

The EU as well as Bulgaria, Croatia, Cyprus, France, Greece; Italy, Malta, Romania, Slovenia and Spain are Contracting Parties to the Agreement establishing GFCM. Pursuant to Article 218(9) of the Treaty on the Functioning of the European Union, the Council of the EU authorizes the European Commission (EC) to negotiate on behalf of the EU in RFMOs when they are called upon to adopt acts with legal effect on matters falling within the EU's competence. Within GFCM, the EU is the main fishing actor in terms of landings, number of vessels and fleet capacity, with Italy accounting for the greatest fleet capacity among EU Member States (MS), and the second-largest capacity among all the Mediterranean riparian states, after Turkey (Table 1).

\section{THE MEDITERRANEAN FISHERIES "GORDIAN KNOT"}

In the Mediterranean, fisheries exploitation has reached high levels coupled with low levels of selectivity (Colloca et al., 2013; Vasilakopoulos et al., 2014; Tserpes et al., 2016). Studies aimed at investigating the trends in Mediterranean stocks have shown that exploitation rates have increased over time for a considerable number of small pelagic and demersal fish stocks (Vasilakopoulos et al., 2014; Tsikliras et al., 2015), combined with an increasing proportion of juveniles in catches (Vasilakopoulos et al., 2014). By 2016, 97\% of shared stocks assessed were reported to be overfished (FAO, 2016a). Despite this, scientific advice has rarely been followed for implementing management (Lleonart and Maynou, 2003; Cardinale and Scarcella, 2017).

Mediterranean fisheries have historically been regulated by input measures in the way of effort regulation, generally accompanied by methods of indirect effort control, such as various technical measures (Colloca et al., 2013; Vasilakopoulos et al., 2014; Damalas, 2015). However, even if effort control systems are properly implemented, it often results in fishing mortality being higher than intended (Stefansson and Rosenberg, 2005), as has been the case for the Mediterranean (Cardinale and Scarcella, 2017). Consequently, management based on technical measures has failed to ensure the long-term sustainability of fisheries and the conservation of sensitive habitats (Tudela, 2004; Colloca et al., 2013). This, alongside with poor or non-existent enforcement of fisheries management measures, has led to a point of no return in the mismanagement and decline of Mediterranean stocks, which is likely to continue if no remedial action is taken (Vasilakopoulos et al., 2014).

This situation has generated a "Gordian knot" in Mediterranean fisheries management, both within the EU (Section a) and GFCM (Section b), that represents a paramount challenge for managers in terms of urgently finding appropriate solutions for reversing decades of overfishing.

\section{(A) THE EUROPEAN MEDITERRANEAN FISHERIES MANAGEMENT CONTEXT (1994-2014)}

Initial interventions to regulate the EU fleet started in the early 90 s, administered by the EC, and aimed at restructuring the EU's fishing fleets by fixing ceilings on fishing capacity by fleet segments (OECD, 2005). These limits apparently reduced the size of the Mediterranean EU fleet, and the limits they set on total tonnage and engine power remained in force. However, fleet modernization schemes, strongly subsidized under the Funding Instrument for Fisheries Guidance and other funding mechanisms, created a technological creep that has perpetuated an unbalance between fishing capacity and efficiency and fish availability that still persists today. For example, in the Balearic Islands (Spain), a reduction in fishing vessels (from 70 in 1977 to 30 in 2009) corresponded to a much steeper increase in average Horse Power (HP) per vessel (from $15 \mathrm{HP}$ in 1977 to $600 \mathrm{HP}$ in 2009) (Quetglas et al., 2013). This perverse development has not only failed to reduce fishing mortality on stocks, but has also constituted a useless expenditure of substantial amounts of public funding initially allocated to solve the problem. In 2009, total subsidies to the European fishing sector were equivalent to 50 percent of the value of total fish catches by the EU in that same year (€6.6 billion; Schroeer et al., 2011).

The first regulation establishing measures for the conservation of fishery resources in EU Mediterranean waters was adopted by the European Council in 1994 (Council Regulation (EC) No 1626/94), a full 10 years after the entry into force of the first Common Fisheries Policy (CFP; 1983) and fisheries management plans for the North East Atlantic. The aim of this Regulation was to lay down a first set of technical measures that would apply 
TABLE 1 | Summary of reported landings, vessels, and fleet capacity of GFCM contracting parties, cooperating non-contracting parties, non-contracting parties, or relevant non-State actors in the Mediterranean and Black Seas.

\begin{tabular}{|c|c|c|c|c|c|c|}
\hline & \multicolumn{2}{|c|}{ Landings } & \multicolumn{2}{|c|}{ Vessels } & \multirow[t]{2}{*}{ Fleet capacity (GT) } & \multirow[t]{2}{*}{$\%$ of total } \\
\hline & Average landing (tons) & $\%$ of total & Number of vessels & $\%$ of total & & \\
\hline EU: & 524,578 & 35.60 & 43,005 & 46.37 & 380,498 & 33.14 \\
\hline Italy & 249,500 & 16.93 & 12,469 & 13.45 & 163,994 & 14.28 \\
\hline Spain & 108,100 & 7.34 & 2,663 & 2.87 & 56,607 & 4.93 \\
\hline Greece & 81,900 & 5.56 & 15,688 & 16.92 & 74,811 & 6.52 \\
\hline Croatia & 42,100 & 2.86 & 7,733 & 8.34 & 53,380 & 4.65 \\
\hline France & 29,900 & 2.03 & 1,461 & 1.58 & 15,777 & 1.37 \\
\hline Bulgaria & 7,715 & 0.52 & 704 & 0.76 & 3,743 & 0.33 \\
\hline Cyprus & 1,749 & 0.12 & 943 & 1.02 & 3,388 & 0.30 \\
\hline Malta & 1,419 & 0.10 & 1,015 & 1.09 & 7,020 & 0.61 \\
\hline Romania & 1,258 & 0.09 & 159 & 0.17 & 790 & 0.07 \\
\hline Slovenia & 937 & 0.06 & 168 & 0.18 & 597 & 0.05 \\
\hline Portugal & - & 0.00 & 2 & 0.00 & 391 & 0.03 \\
\hline \multicolumn{7}{|l|}{ Non-EU: } \\
\hline Turkey & 459,400 & 31.18 & 16,447 & 17.74 & 175,328 & 15.27 \\
\hline Algeria & 115,400 & 7.83 & 4,778 & 5.15 & 69,711 & 6.07 \\
\hline Tunisia & 101,400 & 6.88 & 13,826 & 14.91 & 114,030 & 9.93 \\
\hline Ukraine & 68,900 & 4.68 & 135 & 0.15 & $\mathrm{~N} / \mathrm{A}$ & - \\
\hline Egypt & 67,300 & 4.57 & 2,988 & 3.22 & 72,336 & 6.30 \\
\hline Libya & 41,700 & 2.83 & 4,641 & 5.00 & 164,928 & 14.36 \\
\hline Morocco & 35,600 & 2.42 & 2,146 & 2.31 & 15,354 & 1.34 \\
\hline Russian Federation & 32,000 & 2.17 & 33 & 0.04 & $\mathrm{~N} / \mathrm{A}$ & - \\
\hline Georgia & 12,600 & 0.86 & 47 & 0.05 & $\mathrm{~N} / \mathrm{A}$ & \\
\hline Lebanon & 3,574 & 0.24 & 2,623 & 2.83 & 6,474 & 0.56 \\
\hline Albania & 2,801 & 0.19 & 511 & 0.55 & 10,768 & 0.94 \\
\hline Syrian Arab Republic & 2,768 & 0.19 & 31 & 0.03 & 2,462 & 0.21 \\
\hline Israel & 2,643 & 0.18 & 400 & 0.43 & $\mathrm{~N} / \mathrm{A}$ & - \\
\hline Palestinian Territories & 2,118 & 0.14 & 759 & 0.82 & $\mathrm{~N} / \mathrm{A}$ & - \\
\hline Montenegro & 645 & 0.04 & 135 & 0.15 & 1,309 & 0.11 \\
\hline Monaco & 2 & 0.00 & $\mathrm{~N} / \mathrm{A}$ & & & 0.00 \\
\hline Japan & - & 0,00 & 229 & 0.25 & 134,982 & 11.76 \\
\hline
\end{tabular}

Data for EU have been aggregated (aggregated \% in bold). Modified from FAO (2016b).

equally to all MS fishing in the region. Unfortunately, despite the fact that fisheries in the Mediterranean were already much more weakly regulated that in the North-East Atlantic, Regulation $1626 / 94$ set a weaker double-standard by being adapted to "the particular circumstances" of Mediterranean fisheries.

With the reform of the CFP in 2002 (Council Regulation (EC) $2371 / 2002$ ), the ecosystem approach to fisheries management was endorsed and adopted, along with the objective of achieving the sustainable long-term management of EU fish stocks. However, in the same year, the EC continued to promote a double standard in fisheries management. It presented its Action Plan for Mediterranean fisheries (EC, 2002) to deal with "specific features of the Mediterranean" where "the CFP does not apply in the same way as elsewhere in the Union" though "all species of fish are subject to overexploitation" (EC, 2002). In the following years, MS set effort controls, adopted mostly at the country level, and on the basis of fleet logistics in their exploitation dynamics of multiple stocks, without taking into account the geographical distribution of stocks and the fisheries exploiting them (Cardinale and Scarcella, 2017).

In 2006, that regulation was then replaced by Council Regulation (EC) No 1967/2006-commonly referred to as the MedReg-which included a series of technical measures to regulate fisheries in EU Mediterranean waters. The technical measures adopted under the MedReg have often been inconsistent with scientific evidence; for example, minimum landing sizes for some commercial fishes have been set below sizes at maturity (Mouillot et al., 2011). This lack of sciencebased measures, coupled with poor implementation levels and enforcement, have been detrimental to stocks (Cardinale and Scarcella, 2017) and have led to poorly selective demersal fisheries whose catches are mainly dominated by juveniles (Colloca et al., 2013; Vasilakopoulos et al., 2014; Cardinale and Scarcella, 2017).

The MedReg also introduced the requirement for MS to adopt National Management Plans (NMPs; Art. 19) for certain fisheries 
in their territorial waters. Most of the current 34 NMPs were established years after the 2010 deadline (EC, 2016) while, not surprisingly, monitoring and assessment of their effects on stocks has been very limited.

In December 2013, a reformed CFP entered into force (EU Regulation No 1380/2013), changing the existing fisheries management landscape entirely. Critically, it requires population of fish stocks to be restored and maintained above biomass levels capable of producing maximum sustainable yield (MSY) by 2015 , or by 2020 at the very latest. It requires the precautionary and ecosystem-based approach to fisheries management to be implemented so as to ensure that negative impacts on the marine ecosystem are minimized. It also mandates a gradual implementation of a landing obligation and ban on discards, by avoiding and reducing unwanted catches. The 2013 CFP also laid out a new approach for the EU within RFMOs (see below).

The key tool for restoring and sustainably managing fish stocks under the CFP is intended to be the implementation of multiannual management plans (MAPs). However, nearly four years after the adoption of the CFP, no such plans have yet been established in EU Mediterranean waters.

\section{(B) THE GFCM FISHERIES MANAGEMENT CONTEXT (2003-2016)}

In 2003, the Declaration of the Ministerial Conference for the Sustainable Development of Fisheries in the Mediterranean empowered the SAC to advance GFCM fisheries management based on sound scientific advice. Since 2005, a set of binding measures have been adopted in GFCM, although these mainly have been input control measures, and the majority have been poorly or not implemented at all.

One example arose following repeated advice from SAC (from 2001-2004) to reduce fishing mortality and limit the capture of juveniles, as a measure to address overexploitation. In 2005, GFCM adopted a Recommendation for the immediate implementation of a minimum $40 \mathrm{~mm}$ mesh size for the entire cod-end of demersal trawls (GFCM, 2005). However, only 2 years later, this measure was derogated, allowing cod-end mesh sizes smaller than $40 \mathrm{~mm}$ to operate until 2010 (GFCM, 2007). In 2009, the $40 \mathrm{~mm}$ minimum mesh size was adopted for the entire region (GFCM, 2009), but only from 2012 onwards: a delay of over seven years after the SAC advice. Still today, there are concerns that the $40 \mathrm{~mm}$ mesh size is far from being implemented in the region and its implementation may not be properly monitored.

Close to its 60th anniversary, GFCM launched a process to modernize its legal and institutional framework, following an external performance review in 2009-2011 (GFCM, 2011) which, inter alia, advised GFCM to revise its Agreement so as to align it with the principle of sustainable management laid down in the FAO Code of Conduct for Sustainable Fisheries. This modernization process-in which civil society also took part (Oceana, 2012)_concluded in 2014. The resulting fourth amendment to the GFCM Constitutive Agreement finally included the obligation to halt overfishing so as to achieve MSY, through the adoption of MAPs based on the ecosystem-based approach to fisheries management and the implementation of the precautionary principle.

\section{KNOCK-ON EFFECTS}

The 2013 CFP identifies clear management objectives, along with a timeline for meeting them. It also defines the framework within which the EU must operate in RFMOs. In particular, Article 29 establishes that the EU position must be based on the best available scientific advice, so as to ensure that the precautionary approach is applied, and that fish stocks are managed above levels which can produce MSY, while ensuring the profitability of the fishery, in line with Articles 2.2 and 2.5c of the CFP. Furthermore, the EU has the legal obligation to "seek to lead the process of strengthening the performance of RFMOs so as to better enable them to conserve and manage marine living resources under their purview."

This new EU approach to RFMOs entered into force while the process to amend the GFCM Agreement was ongoing. The EU was the leading voice in the process, promoting and contributing to the Task Force working directly on the amendment of the Agreement. Indeed, the $2013 \mathrm{CFP}$ obliged the EU to ensure that both the precautionary approach and ecosystem-based management would be reflected and embedded in the GFCM. The final GFCM text was strongly influenced by the 2013 CFP, which is believed to have produced a knock-on effect on the reform of GFCM.

The synergy of the two revised regulations, the 2013 CFP and the 2014 GFCM Agreement, together hold the potential to drive the reshaping of fisheries management in the Mediterranean. Furthermore, the focus on multiannual management plans that include clear objectives, and are supported by effective control and enforcement, has been indicated as the alternative management approach that could reverse the decline of Mediterranean stocks (Vasilakopoulos et al., 2014; Cardinale and Scarcella, 2017). The Mediterranean fisheries crisis has been building for decades: the new regulatory tools provide hope and a sound basis for rebuilding fish stocks to levels that can produce MSY.

\section{DEMERSAL FISHERIES IN THE STRAIT OF SICILY, A POTENTIAL TURNING POINT FOR SCIENCE-BASED MANAGEMENT}

The first case in which the 2013 CFP and the 2014 GFCM Agreement have both been applied was the establishment of a MAP for the fisheries targeting deep-water rose shrimp (Parapenaeus longirostris) and, secondarily, European hake (Merluccius merluccius) in the Strait of Sicily (GSA 12 to 16). These fisheries are carried out by bottom trawlers from Italy, Malta and Tunisia.

Fishing mortality for hake and deep-water rose shrimp has been estimated at 4.5 and 1.2 times, respectively, above sustainable levels (FAO-GFCM, 2015). Since 2006, GFCM prioritized hake in GSA $12-16$ on its agenda due to the high level of overfishing and catches of juveniles (GFCM, 
2006). Since then, however, no management had been put in force. Finally, in 2014, following the adoption of the 2014 GFCM Agreement, the EU tabled a proposal to address the overfishing of key demersal stocks in the Strait of Sicily. While this proposal was not adopted at the time, the SAC was requested to provide comprehensive advice in the context of a multiannual management plan (FAO-GFCM, 2014). To achieve and sustainably manage key commercial stocks of hake and deep-water rose shrimp ( $\left.\mathrm{F}_{\mathrm{MSY}}\right)$, the $\mathrm{SAC}$ advised a reduction of fishing mortality by $20 \%$ for deep-water rose shrimp and $70 \%$ for hake, to be progressively achieved by 2020 through the adoption of a MAP, which also included three Fisheries Restricted Areas to be closed to bottom trawling to reduce fishing mortality of juvenile hake (SAC-SRC-CM, 2016). This scientific recommendation allowed the EU to table a proposal at the 40th GFCM Commission, which was then adopted with consensus in May 2016 (GFCM, 2016).

Compared to other management strategies in place until now in the Mediterranean, this newly adopted MAP represented a significant advance, in that it includes the explicit objective of recovering stocks to MSY, in line with both the 2013 CFP and 2014 GFCM Agreement, and specifically by 2020, in line with the CFP obligation. This consistency with the CFP was especially important, considering that the EU fleet has the highest stake in this fishery, with $82 \%$ of all vessels involved in the fishery flying EU flags (Gancitano et al., 2016).

\section{LESSON LEARNED TO MAKE A CONCRETE CHANGE IN THE MEDITERRANEAN FISHERIES MANAGEMENT}

In conclusion, despite the fact that policy tools were already in place during the past two decades (i.e., UNCLOS, FAO Code of Conduct, 2002 CFP) and already provided a framework to halt overfishing, they have been disregarded in the Mediterranean due to lack of implementation and enforcement. In particular, EU fisheries management in the region has been characterized by weak institutional structures and poor levels of compliance (Smith and Garcia, 2014; Vasilakopoulos et al., 2014). Under the MedRed, MS have failed to take responsibility for properly translating the regulation into management, and EU Mediterranean fisheries management has proven ineffective for

\section{REFERENCES}

Cardinale, M., and Scarcella, G. (2017). Mediterranean Sea: a failure of the European fisheries management system. Front. Mar. Sci. 4:72. doi: 10.3389/fmars.2017.00072

Colloca, F., Cardinale, M., Maynou, F., Giannoulaki, M., Scarcella, G., Jenko, K., et al. (2013). Rebuilding Mediterranean fisheries: a new paradigm for ecological sustainability in single species population models. Fish Fish. 14, 89-109. doi: 10.1111/j.1467-2979.2011. 00453.x

Damalas, D. (2015). Mission impossible: discard management plans for the EU Mediterranean fisheries under the reformed Common Fisheries Policy. Fish. Res. 165, 96-99 doi: 10.1016/j.fishres.2015.01.006 achieving the objectives of the former 2002 CFP of sustainably managing fish stocks.

The current complexity of the situation gives only two options: untie the Gordian knot with a strong commitment from all parties involved, and on the basis of scientific advice; or cut it, jeopardizing Mediterranean stocks forever. Here we consider the following:

(i) Input control measures have historically been considered the palliative cure to deal with Mediterranean fisheries. However, that approach, combined with weak control and enforcement, has contributed to fostering overfishing over decades. Output control rules should be the basis of new multiannual management plans, together with measures aimed at reducing unwanted catches and implementing ecosystem-based management.

(ii) The MAP for demersal shared stocks in the Strait of Sicily has represented a tipping point in Mediterranean fisheries management. Clearly this development in science-based management has been influenced by the principles and obligations of the 2013 CFP on EU fisheries management priorities, as well by the reshaped objectives and approach of GFCM. However, this approach is still in its embryonic phase and needs to be proven and tested by real commitment from the parties involved. Either the plan is properly implemented, or if not, it would then represent yet another failure for Mediterranean fisheries managementand possibly the ultimate one.

(iii) Based on the dynamics of fisheries policy and implementation over the last two decades in the region, it is clear that legislation will not deliver the desired results if implementation and enforcement are not placed equally high on the policy agenda. To achieve the maximum benefit of the synergies between the 2013 CFP and 2014 GFCM Agreement for driving the recovery of Mediterranean fish stocks, it is therefore critical that both policy tools must be urgently and fully implemented and enforced. This responsibility rests directly on the EU MS and other Mediterranean countries, in the interests of their fishing futures.

\section{AUTHOR CONTRIBUTIONS}

IV, AP, and MC contributed to the conceptualization, writing of the original draft, and revision of the paper.

EC (2002). Communication from the Commission to the Council and the European Parliament of 9 October 2002 Laying Down a Community Action Plan for the Conservation and Sustainable Exploitation of the Fisheries Resources in the Mediterranean Sea under the Common Fisheries Policy. European Commission, COM 2002-535.

EC (2016). Public Consultation, Multiannual Plan for the Fisheries Exploiting Demersal stOcks in the Western Mediterranean Sea. Background consultation document; European Commission. Available online at: https://ec.europa.eu/ info/sites/info/files/consultation-multi-annual-plan-western-mediterraneanbackground_document_en_0.pdf

FAO (1999). General Fisheries Commission for the Mediterranean. Report of the first session of the Scientific Advisory Committee; FAO Fisheries Report No. 601, Rome, Italy, Rome, 52. 
FAO (2016a). General Fisheries Commission for the Mediterranean. Report of the eighteenth session of the Scientific Advisory Committee on Fisheries; FAO Fisheries and Aquaculture Report No. 1154, Nicosia; Rome.

FAO (2016b). The State of Mediterranean and Black Sea Fisheries. General Fisheries Commission for the Mediterranean. Rome, 152.

FAO-GFCM (2014). FAO General Fisheries Commission for the Mediterranean. Report of the thirty-eighth session. FAO headquarters; GFCM Report. No. 38, Rome, 108.

FAO-GFCM (2015). FAO General Fisheries Commission for the Mediterranean. Report of the seventeenth session of the Scientific Advisory Committee. FAO headquarters; FAO Fisheries and Aquaculture Report No.1110, Rome, 300.

Gancitano, V., Milisensa, G., Ben Meriem, S., Colloca, F., Arneri, E., Ceriola, L., et al. (2016). Stock Assessment form of Hake (M. merluccius) in Combined GSA 12-16 Reference Year: 2007-2015 Reporting Year: 2016. GFCM Working Group on dermersal stock assessment.

GFCM (2005). Recommendation CM-GFCM/29/2005/1 on the Management of Certain Fisheries Exploiting Demersal and Deep-Water Species and the Establishment of a Fisheries Restricted Area below $1000 \mathrm{~m}$.

GFCM (2006). Recommendation CM-GFCM/30/2006/1 on the Management of Certain Fisheries Exploiting Demersal and Small Pelagic.

GFCM (2007). Recommendation CM-GFCM/31/2007/1 on the Mesh Size of Trawl Nets Exploiting Demersal Resources.

GFCM (2009). Recommendation CM-GFCM/33/2009/2 on the Minimum Mesh Size in the Codend of Demersal Trawl Nets.

GFCM (2011). Performance Review of the General Fisheries Commission for the Mediterranean and Black Sea. Available online at: http://151.1.154.86/ GfcmWebSite/TaskForce/2013/GFCM_PerformanceReview_2011.pdf

GFCM (2016). Recommendation CM-GFCM/40/2016/4 Establishing a Multiannual Management Plan for the Fisheries Exploiting European Hake and Deep-Water Rose Shrimp in the Strait of Sicily (GSA 12 to 16).

Lleonart, J., and Maynou, F. (2003). Fish stock assessment in the Mediterranean: state of the art. Sci. Mar. 67, 37-49. doi: 10.3989/scimar.2003.67s137

Mouillot, D., Albouy, C., Guilhaumon, F., Ben Rais Lasram, F., Coll, M., Devictor, V., et al. (2011). Protected and Threatened components of fish biodiversity in the Mediterranean Sea. Curr. Biol. 21, 1044-1050. doi: 10.1016/j.cub.2011.05.005

Oceana (2012). Oceana Submission to the GFCM $36^{\text {th }}$ Session of the Commission Marrakech, 14-19 May 2012. There is Still a Future for Mediterranean Fisheries. Available online at: http://oceana.org/sites/default/files/euo/OCEANA_ GFCM1.pdf

OECD (2005). Review of Fisheries in OECD Countries: Policies and Summary Statistics 2005. Paris: OECD Publishing.

Quetglas, A., Ordines, F., Hidalgo, M., Monserrat, S., Ruiz, S., Amores, A., et al. (2013). Synchronous combined effects of fishing and climate within a demersal community. ICES J. Mar. Sci. 70, 319-328. doi: 10.1093/icesjms/fss181
SAC-SRC-CM (2016). Scientific Advisory Committee (SAC). Report of Subregional Committee for the Central Mediterranean (SRC-CM). GFCM Headquarters, Rome, 21.

Schroeer, A., Sakai, C., Vulperhorst, V., Bialas, A., and Cornax, M. J. (2011). The European Union and Fishing Subsidies. OCEANA Report, 28.

Smith, A. D. M., and Garcia, S. M. (2014). Fishery management: contrasts in the Mediterranean and the Atlantic. Curr. Biol. 24:17. doi: 10.1016/j.cub.2014.07.031

STECF (2015). Scientific, Technical and Economic Committee for Fisheries (STECF)-Standardization Procedures for Data Preparation, Stock Assessment Methods and Estimate of MSY Reference Points for Mediterranean Stocks (STECF-15-11). (2015). Publications Office of the European Union; EUR 27408 EN; JRC 97017, Luxembourg, 104.

Stefansson, G., and Rosenberg, A. A. (2005). Combining control measures for more effective management of fisheries under uncertainty: quotas, effort limitation and protected areas. Philos. Trans. R. Soc. B. 360, 133-146. doi: $10.1098 /$ rstb.2004.1579

Tserpes, G., Nikolioudakis, N., Maravelias, C., Carvalho, N., and Merino, G. (2016). Viability and management targets of Mediterranean demersal fisheries: the case of the Aegean Sea. PLoS ONE 11:e0168694. doi: 10.1371/journal.pone.0168694

Tsikliras, A. C., Dinouli, A., Tsiros, V. Z., and Tsalkou, E. (2015). The Mediterranean and Black Sea fisheries at risk from overexploitation. PLoS ONE 10:e0121188. doi: 10.1371/journal.pone.0121188

Tudela, S. (2004). Ecosystem Effect of Fishing in the Mediterranean: an Analysis of the Major Threats of Fishing Gear and Practices to Biodiversity and Marine Habits. FAO Studies and Review, Rome.

UN (1995). United Nations. Agreement for the Implementation of the Provisions of the United Nations Convention on the Law of the Sea of 10 December 1982 relating to the Conservation and Management of Straddling Fish Stocks and Highly Migratory Fish Stocks (UN Fish Stocks Agreement). United Nations Conference on straddling Fish Stocks and Highly Migratory Fish Stocks, New York, NY.

Vasilakopoulos, P., Maravelias, C. D., and Tserpes, G. (2014). The alarming decline of Mediterranean fish stocks. Curr. Biol. 24:14. doi: 10.1016/j.cub.2014.05.070

Conflict of Interest Statement: The authors declare that the research was conducted in the absence of any commercial or financial relationships that could be construed as a potential conflict of interest.

Copyright (c) 2017 Vielmini, Perry and Cornax. This is an open-access article distributed under the terms of the Creative Commons Attribution License (CC BY). The use, distribution or reproduction in other forums is permitted, provided the original author(s) or licensor are credited and that the original publication in this journal is cited, in accordance with accepted academic practice. No use, distribution or reproduction is permitted which does not comply with these terms. 